\title{
PRE-SCREENING TPMT STATUS OF LIVER TRANSPLANT PATIENTS FOR AZATHIOPRINE THERAPY-A SINGLE CENTRE EXPERIENCE FROM SOUTH INDIA
}

\author{
SAGI SASIDHARAN ${ }^{1}$, EMMANUEL JAMES ${ }^{1}$, SUDHINDRAN S. ${ }^{2}$ \\ 1Department of Pharmacy Practice, Amrita School of Pharmacy, Amrita Vishwa Vidyapeetham, Amrita University, AIMS Health Science \\ Campus, Kochi, India, 2Department of Gastrointestinal Surgery, Amrita Institute of Medical Sciences and Research Centre, Amrita Vishwa \\ Vidyapeetham, Amrita University, AIMS Health Science Campus, Kochi, India \\ Email: emmanuelj@aims.amrita.edu \\ Received: 12 Oct 2016 Revised and Accepted: 07 Dec 2016
}

\section{ABSTRACT}

Objective: To assess azathioprine-induced bone marrow toxicity and its correlation with thiopurine methyltransferase (TPMT) mutation in liver transplant patients who develop myelosuppression while on azathioprine therapy.

Methods: A prospective observational study was conducted from $1^{\text {st }}$ September 2014 to $30^{\text {th }}$ June 2015 on 60 liver transplant patients who were tested for TPMT allele activity prior to receiving azathioprine. Haemoglobin levels, platelet counts and white blood cell counts of the patients were monitored for the occurrence of myelotoxicity. Patients who underwent liver transplant during the retrospective period from 1 st September 2011 to $31^{\text {st }}$ August 2014 and who developed myelosuppression while on azathioprine therapy were also tested for TPMT genotype.

Results: A total of 76 liver transplant patients were tested for TPMT mutation. Prevalence of TPMT mutation in the study patients was $3.95 \%$. The heterozygous $T P M T^{*} 1{ }^{*} 3 C$ genotype was traced in $2.63 \%$ of the patients while $1.32 \%$ of patients were homozygous for $T P M T^{*} 3 C$ allele. Interestingly $43.4 \%$ of patients with wild allele also showed azathioprine-induced myelosuppression. Azathioprine dose of 100 mg showed a higher degree of myelotoxicity than lower doses. Haematological indices of $42.1 \%$ of patients normalised on cessation of azathioprine therapy.

Conclusion: Myelosuppression following the introduction of azathioprine was observed in patients with both 'mutant' and 'wild-type' alleles. Therefore a cautious approach has to be taken in pre-screening liver transplant recipients for TPMT allele determination in our population. The absence of TPMT mutation does not ensure freedom from myelosuppression. Hence regular monitoring of haematological indices of such patients receiving thiopurine therapy should be continued.

Keywords: Azathioprine, Immunosuppressive regimens, Liver transplantation, Myelosuppression, Thiopurine methyltransferase, TPMT genotype testing

(C) 2017 The Authors. Published by Innovare Academic Sciences Pvt Ltd. This is an open access article under the CC BY license (http://creativecommons.org/licenses/by/4. 0/) DOI: http://dx.doi.org/10.22159/ijpps.2017v9i2.15630

\section{INTRODUCTION}

Azathioprine is an immunosuppressant used in patients with organ transplant and autoimmune diseases. It is used to prevent rejection following liver transplantation. Though mycophenolate mofetil has replaced azathioprine in some liver transplant (LT) centres as an immunosuppressant, the clinical benefit of mycophenolate mofetil over azathioprine is questionable. Azathioprine has still a role in maintaining immunosuppression in liver transplant patients especially those taking tacrolimus-based regimens [1].
Azathioprine is a prodrug of mercaptopurine and thiopurine smethyltransferase (TPMT) is one of the main enzymes that inactivate mercaptopurine. Azathioprine is metabolised in an anabolic pathway to cytotoxic 6-thioguanine and 6methylmercaptopurine (fig. 1). With a true deficiency of TPMT, there is an increased chance of accumulation of cytotoxic metabolites leading to bone marrow toxicity and myelosuppression. Hence there is a risk of bone marrow suppression in all patients receiving azathioprine. This adverse effect is dose-dependent and can be managed by dose reduction or discontinuation of azathioprine [2, 3].

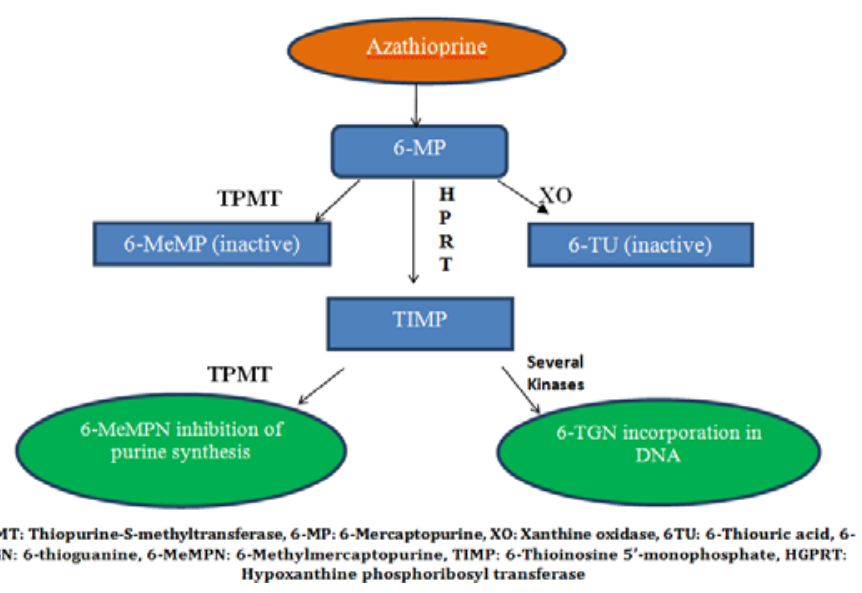

Fig. 1: Metabolism pathway of azathioprine 
Variation in TPMT activity is related to three distinct TMPT mutations and can be identified by TPMT genotyping based on a polymerase chain reaction. Patients with high TPMT activity (wildtype) are found to have two normal alleles. Patients with two nonfunctional alleles (homozygous) have low or absent TPMT activity and those with one non-functional allele (heterozygous) have intermediate activity [4]. The following alleles are related to decreased levels of TPMT: TPMT*2, TPMT*3A, TPMT*3B, TPMT*3C. Hence it is suggested that determination of TPMT genotype in patients on azathioprine therapy may improve our ability to manage these patients more effectively and safely by reducing the dose or discontinuing the therapy [3]. The practice of monitoring thiopurine metabolism has been well established in several western countries where the national guidelines suggest that TPMT genotype and/or phenotype determination should be considered for all patients prior to initiation of azathioprine treatment. But there are also reports $[5,6]$ that non-TPMT determinants may also play a role in azathioprine toxicity.

Though a number of studies [7-14] are available on polymorphism of TPMT gene, data on liver transplant patients are scarce from India. Hence the objective of our study was to assess the bone marrow toxicity induced by azathioprine immunosuppressive therapy and to identify any correlation with TPMT mutation and myelosuppression in LT patients receiving azathioprine.

\section{MATERIALS AND METHODS}

A prospective observational study was conducted on LT patients admitted to the department of gastrointestinal surgery, Amrita Institute of Medical Sciences and Research Centre Kochi, India during $1^{\text {st }}$ September 2014 to $30^{\text {th }}$ June 2015 and who underwent TPMT genotyping. Additionally, patients who underwent LT during the retrospective period from $1^{\text {st }}$ September 2011 to $31^{\text {st }}$ August 2014 and who developed myelosuppression while on azathioprine (AZA) therapy were tested for TPMT genotype. The study was done with the approval of the Institutional Review Board (Pharma/2015/04 dated 01.09.2014). A study information sheet regarding the purpose, risks and benefits of the study was distributed to each of the participants and informed signed consent was obtained from each patient prior to the study. Patients who died within six months of LT were excluded. LT patients of all age groups were included. The demographic details of the patients, social habits, co-morbid conditions, laboratory values and details of immunesuppressive regimens were collected from the medical records and by direct interaction with patients/their caregivers and also from digital hospital information system. All the LT patients were tested for TPMT allele in the molecular biology laboratory of the hospital using Vienna Lab PGX-TPMT Strip Assay® kit. The kit was capable of detecting the genetic variants of TPMT alleles *1, *2, *3A, *3B and *3C. Bone marrow suppression was defined as a white blood cell count of less than $3.5 \times 10^{9} / \mathrm{l}$, or a platelet count of less than 150 $\times 10^{9} / \mathrm{l}$ or a haemoglobin level below $11 \mathrm{~g} / \mathrm{dl}$.

\section{TPMT activity definitions [4]}

High/normal TPMT activity $>13.7$ units/ml RBC (Red blood corpuscles); Intermediate TPMT activity between 5 and 13.7 units/ml RBC; Low TPMT activity $<5$ units/ml RBC. The posttransplant status, the introduction of azathioprine therapy, baseline haematological parameters and adverse effects of immunesuppressive regimens were assessed in all the LT patients.

\section{RESULTS}

A total of 76 patients, consisting of 60 prospective and 16 retrospective patients, were tested for TPMT genotype. There were 132 patients who were on azathioprine therapy during the retrospective period and severe myelosuppression was observed in 16 of these patients. Hence these 16 patients were tested for TPMT activity. The mean age of the 76 patients tested for TPMT genotype was $43.0 \pm 17.1$ y (Median age 49 y, Range $1-68$ y). The majority (47, $61.8 \%)$ of patients were in the age group 41-60 y. Males constituted $59(77.6 \%)$ of the study patients. Thirty-one $(40.8 \%)$ patients were alcoholics and $24(31.6 \%)$ were smokers. Indications for LT were a chronic liver disease in $64(84.2 \%)$ patients and acute liver disease in the remaining $12(15.8 \%)$ patients. The co-morbid conditions of LT patients included diabetes in 25 (32.9\%), hypertension in 9 $(11.8 \%)$, tuberculosis in $3(3.9 \%)$, asthma in $4(5.3 \%)$ and dyslipidaemia in $4(5.3 \%)$ patients. Out of the 16 retrospective patients tested for TPMT activity, 15 had wild-type TPMT allele. TPMT*2, *3A, *3B alleles were absent in our study patients. Distribution of genotype frequencies of TPMT in the liver transplant patients are shown in table 1 .

Table 1: Distribution of allele/genotype frequencies of TPMT in the liver transplant patients

\begin{tabular}{ll}
\hline Type of allele & No. (\%) of alleles (n=152) \\
\hline TPMT*1 & $148(97.37)$ \\
TPMT*3C & $4(2.63)$ \\
Genotype & No. (\%) of patients (n=76) \\
Homozygous wild & \\
$\quad$ TPMT*1/TPMT*1 & $73(96.1)$ \\
Mutant genotypes & $3(3.9)$ \\
Homozygous mutant & $1(1.3)$ \\
$\quad$ TPMT*3C/TPMT*3C & \\
Heterozygous mutant & $2(2.6)$ \\
$\quad$ TPMT*1+TPMT*3C & \\
\hline
\end{tabular}

Out of 76 patients tested for TPMT, normal activity (TPMT $* 1$, wild allele) was detected in $73(96.1 \%)$ patients. Three patients had mutant alleles of which 1 patient (1.3\%) had low levels of enzyme activity and 2 patients $(2.6 \%)$ had intermediate enzyme activity. Decrease in haematological counts was observed more with an immunosuppressive regimen containing $100 \mathrm{mg}$ dose of azathioprine than lower doses (table 2). Azathioprine was used in combination with tacrolimus and steroids. The median dose of azathioprine was $75 \mathrm{mg}$ daily.

Table 2: Hematological adverse effects of various doses of azathioprine as combination therapy in the study patients $(n=44)$

\begin{tabular}{|c|c|c|c|}
\hline $\begin{array}{l}\text { AZA } \\
\text { dose }\end{array}$ & $\begin{array}{l}\text { No. of patients with decrease in } \mathrm{Hb} \\
\text { count }(<11 \mathrm{~g} / \mathrm{dl})\end{array}$ & $\begin{array}{l}\text { No. of patients with decrease in WBC count } \\
(<3.5 \mathrm{~K} / \mathrm{ul})\end{array}$ & $\begin{array}{l}\text { No. of patients with decrease in } \\
\text { platelet count }(<150 \mathrm{~K} / \mathrm{ul})\end{array}$ \\
\hline $25 \mathrm{mg}$ & 1 & 1 & 1 \\
\hline $50 \mathrm{mg}$ & 5 & 5 & 6 \\
\hline $75 \mathrm{mg}$ & 0 & 2 & 1 \\
\hline $100 \mathrm{mg}$ & 6 & 7 & 9 \\
\hline
\end{tabular}

The onset of adverse effects in patients on azathioprine combination therapy is shown in table 3. The majority of patients showed signs of bone marrow suppression within 1 to 5 mo of starting azathioprine combination therapy, though some patients exhibited more than one type of haematological adverse effects. 
Table 3: Onset of hematological adverse effects in patients on azathioprine combination therapy

\begin{tabular}{llll}
\hline $\begin{array}{l}\text { Onset of adverse } \\
\text { effects }\end{array}$ & $\begin{array}{l}\text { No. (\%) of patients with decreased } \\
\text { Haemoglobin levels }\end{array}$ & $\begin{array}{l}\text { No.(\%) of patients with } \\
\text { decreased } \\
\text { WBC counts }\end{array}$ & $\begin{array}{l}\text { No.(\%) of patients with } \\
\text { decreased Platelet counts }\end{array}$ \\
\hline$<1$ month & $5(11.3)$ & $3(6.81)$ & $\begin{array}{l}\text { Total No. (\%) of } \\
\text { patients }\end{array}$ \\
1-5months & $7(15.9)$ & $8(18.2)$ & $15(15.9)$ \\
$6-12$ mo & 0 & 0 & $27(27.3)$ \\
\hline
\end{tabular}

Thirty-nine patients on azathioprine regimen were converted to other immunosuppressive therapy and haematological profiles of $32(42.1 \%)$ patients normalised on discontinuing azathioprine therapy. The maximum decrease in haematological counts occurred during 1-5 mo after starting azathioprine. Thirty-three (43.4\%) patients with 'wild allele' showed bone marrow suppression after azathioprine therapy. The incidence of leucopenia was $40.8 \%$ with azathioprine therapy and $26.3 \%$ with mycophenolate mofetil therapy. Table 4 shows the mean variation in haematological counts from baseline. There was $69.7 \%$ decrease in WBC counts from mean baseline value and $9.65 \%$ decrease in platelet (PLT) counts from the mean baseline platelet count in patients on azathioprine therapy.

Table 4: Change in hematological counts from baseline of patients on azathioprine therapy

\begin{tabular}{lll}
\hline Parameters & $\begin{array}{l}\text { Hb level (g/d) } \\
(<\mathbf{1 1})\end{array}$ & $\begin{array}{l}\text { WBC count(K/ul) } \\
(<3.5)\end{array}$ \\
\hline Mean baseline count (2weeks prior to AZA therapy) & $9.93 \pm 1.5$ & $10.9 \pm 9.3$ \\
Mean variation from baseline & $10.7 \pm 1.9$ & $3.3 \pm 0.8$ \\
\% change from baseline & $\mathbf{7 . 7 5 \%}$ & $150.2 \pm 146.4$ \\
& $\mathbf{7}$ & $135.7 \pm 54.7$ \\
\hline
\end{tabular}

Data expressed as mean $\pm \mathrm{SD}(\mathrm{n}=27$ for $\mathrm{Hb}, 31$ for WBC and 29 for PLT)

Fig. 2 represents the time of introduction of azathioprine therapy in post-transplant patients. Azathioprine was introduced in 11 (34.3\%) patients 1 mo after transplantation and 10 (31.2\%) patients were started on azathioprine in less than one month of LT and the remaining $39(65 \%)$ patients received azathioprine 2-6 mo after LT.

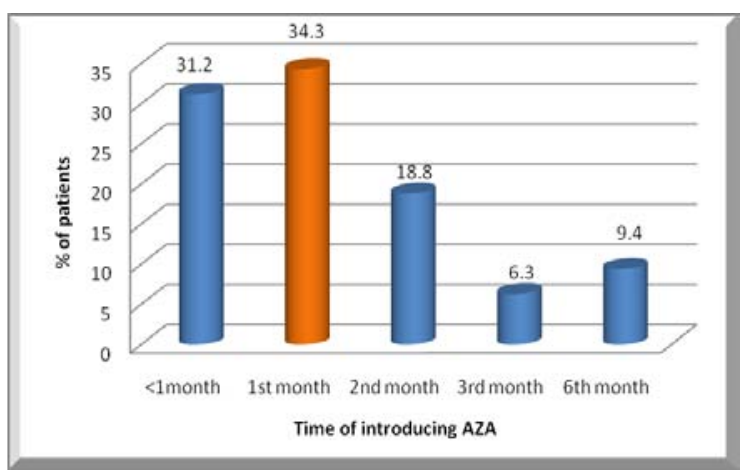

Fig. 2: Time of introduction of AZA in LT patients $(n=60)$ in the prospective study

\section{DISCUSSION}

Azathioprine immunosuppressive therapy is used in LT patients for prevention of rejection by inhibiting the proliferation of lymphocytes. However, azathioprine has a generalised effect on bone marrow, inhibiting production of blood-forming cells leading to leucopenia and thrombocytopenia [15]. Genetic variation in TPMT enzyme has been related to the occurrence of toxicity with thiopurine treatment. More than 27 mutations are now documented, but the clinical relevance of some of them remains unclear [16]. TPMT*3A, TPMT*3C, and TPMT*2 represent the most prevalent mutant alleles in Caucasians and Asians, resulting from genetic polymorphism; $6-11 \%$ of mutations account for 'intermediate' and $0.3 \%$ 'low' thiopurine methyltransferase activity [16]. TPMT*3A, the most common variant, has $5 \%$ frequency in Caucasians. The second most frequent variant, TPMT*3C occurs at a frequency of $2 \%$ in Asian populations $[17,18]$. The present study aimed to evaluate the utility of TPMT allele determination in reducing bone marrow toxicity of azathioprine when used in post-LT patients.
Our study revealed that there is an increased prevalence of TPMT mutation $(3.9 \%)$ in the study patients. Intermediate TPMT activity was seen in $2.6 \%$ and low activity in $1.3 \%$ of our patients (table 1 ). A previous study [8] conducted on 326 healthy individuals from southern India reported a prevalence of $97.2 \%$ for the 'wild-type' allele and $2.76 \%$ for heterozygous mutation with the absence of any homozygous mutation. TPMT*3A was absent in the study patients and the heterozygous variants were TPMT* $1 /{ }^{*} 2, * 1 / * 3 \mathrm{~B}$ and $* 1 / * 3 \mathrm{C}$. The prevalence of 'wild-type' allele in our LT patients was almost comparable (96.1\%), but there was one homozygous mutation and TPMT*3C was the only mutant allele.

When the adverse effects were looked into, 33 (43.42\%) patients with 'wild allele' had the propensity to cause decreased haematological counts while on azathioprine therapy revealing that myelosuppression was more often caused by factors other than TPMT mutation. When azathioprine immunosuppressive therapy was compared with nonazathioprine immunosuppressive therapy, leucopenia was relatively two-fold higher in patients on azathioprine therapy and thrombocytopenia was equally observed in both immunosuppressive therapies. In the retrospective design, we selected those 16 patients who exhibited myelotoxicity while on azathioprine specifically to assess TPMT mutation in which one patient was detected with 'intermediate' TPMT activity. In our study, azathioprine or mycophenolate mofetil was used as an adjunct to tacrolimus therapy in post-LT patients. But azathioprine was found to be 4 times cheaper than mycophenolate mofetil and was equally effective.

An observational study was done by Gisbert et al. [19] suggests that bone marrow suppression can occur at any time after commencing treatment with azathioprine and more frequently during the first month. Contrary to the above study, our study reveals that the occurrence of bone marrow toxicity was predominantly between 1 and $5 \mathrm{mo}$ after the introduction of azathioprine therapy.

In the present study, the risk of bone marrow suppression was relatively high in patients on azathioprine therapy when compared to patients on other immunosuppressive regimens specifically those containing mycophenolate mofetil. The incidence of leucopenia was $40.8 \%$ with azathioprine therapy and $26.3 \%$ with mycophenolate mofetil therapy. But these results are contradictory to randomised double-blind comparative study [20] by Wiesner et al. which showed that the incidence of leucopenia was more in patients on mycophenolate mofetil (10.1\%) compared to patients on azathioprine (7.3\%). 
It could be speculated that the cause of bone marrow suppression in patients with 'wild' and 'mutant' alleles was azathioprine therapy as the haematological indices normalised on discontinuation of azathioprine. There are studies [21-24] on the relationship between 'low' TPMT activity and the adverse effects of azathioprine and other thiopurines. Some of these studies [23, 24] show a notable increase in adverse effects such as bone marrow toxicity in patients with a mutated TPMT gene. On the other hand, other studies [5, 6] suggest that azathioprine-induced adverse effects can be caused by factors other than TPMT mutations. Our results are in agreement with the study [21] which suggests that myelosuppression during azathioprine therapy in LT patients are caused by factors other than mutations leading to reduced TPMT activity. This study from UK suggested that TPMT genotyping do not predict bone marrow suppression in LT patients. Non-TPMT determinants were suggested as a cause of azathioprine-induced myelosuppression in inflammatory bowel disease patients taking the drug [5]. The adverse effects caused by azathioprine may also be influenced by the genotype of the donor since the liver is the principal site of 6-MP methylation [21]

Though the frequency of TPMT mutation is much lower in Asians as compared to Caucasians the incidence of myelosuppression is similar to that seen in patients of European heritage. A recent study [25] on Korean patients with Crohn's disease treated with thiopurines found that myelosuppression was associated more with a mutation in NUDT15 than TPMT. NUDT15 polymorphism was also related to mercaptopurine intolerance in Taiwan Chinese children with acute lymphoblastic leukaemia [26]. NUDT15 variants are very rare in individuals of European and African ancestry, but are relatively common in people of Asian descent $[6,27]$. This could be the reason for the high frequency of thiopurine intolerance in Asian populations despite the low frequency of TPMT variants. Hence NUDT15 can be a target for future studies involving our LT patients who require azathioprine. NUDT15 encodes a nucleoside diphosphatase and is a safeguard mechanism in mammalian cells to minimise DNA damage and avoid subsequent repair and apoptosis [28].

In our study, the test kit for TPMT allele determination was capable of detecting only five TPMT variants $\left(* 1, * 2, * 3 \mathrm{~A},{ }^{*} 3 \mathrm{~B}\right.$ and $\left.{ }^{*} 3 \mathrm{C}\right)$. As more than 27 variants have been identified for TPMT gene, it may be possible that the variants not detected in our study might have also been involved in causing myelotoxicity. Even though it is clear that patients with severe deficiency should not receive azathioprine because of the high risk of adverse effects, it is also well known that TPMT deficiency explains only a portion of all azathioprine-related adverse effects [5]. Consequently, opinion is still divided as to whether TMPT activity determination and TPMT genotyping are needed prior to starting azathioprine or 6-MP therapy in Asian patients. Based on our study TPMT allele testing should not be made mandatory in LT patients as a pre-screening test considering the high cost Rs 5500 per test) of TPMT genotyping. But regular monitoring of haematological indices of LT patients receiving thiopurine therapy should be continued.

\section{CONCLUSION}

The prevalence of TPMT mutation among liver transplant patients treated with azathioprine was $3.95 \%$, the majority being heterozygous genotype (TPMT*1/TPMT*3C). However, azathioprine-induced myelosuppression occurred in $43 \%$ of patients with 'wild type' TPMT as well. Therefore a cautious approach has to be taken in pre-screening liver transplant recipients for TPMT allele determination in South Indian population prior to transplantation. Further genetic studies in this population are needed to evaluate other mutations involved.

\section{ACKNOWLEDGMENT}

We are grateful to the patients for their participation in the study. Our sincere appreciation to Dr. Prem Nair, Medical Director, Amrita Institute of Medical sciences and Dr. Shanthi Nair, Dean of Research, Amrita Vishwa Vidyapeetham, Amrita University for providing the facilities to carry out the study.

\section{CONFLICTS OF INTERESTS}

Declared none

\section{REFERENCES}

1. Germani G, Plaguezuelo M, Villamil F, Vaghjiani S, Tsochatzis E, Andreana L, et al. Azathioprine in liver transplantation: a reevaluation of its use and a comparison with mycophenolate mofetil. Am J Transplant 2009;9:1725-31.

2. Tai HL, Krynetski EY, Yates CR, Loennechen T, Fessing MY, Krynetskaia NF, et al. Thiopurine S-methyltransferase deficiency: two nucleotide transitions define the most prevalent mutant allele associated with loss of catalytic activity in caucasians. Am J Hum Genet 1996;58:694-702.

3. Relling MV, Gardner EE, Sandborn WJ, Schmiegelow K, Pui CH, Yee SW, et al. Clinical pharmacogenetics implementation consortium guidelines for thiopurine methyltransferase genotype and thiopurine dosing. Clin Pharmacol Ther 2011;89:387-91.

4. 6-mercaptopurine (6-MP) metabolite monitoring and TPMT testing in the treatment of inflammatory bowel disease with 6-MP or azathioprine. Available from: http://www.uptodate.com/ contents/6-mercaptopurine-6-mp-metabolite-monitoring-andtpmt-testing. [Last accessed on 01 Jul 2015]

5. Katsanos K, EV Tsianos. Non-TPMT determinants of azathioprine toxicity in inflammatory bowel disease. Ann Gastroenterol 2010;23:95-101.

6. Yang SK, Hong M, Baek J, Choi H, Zhao W, Jung Y, et al. A common missense variant in NUDT15 confers susceptibility to thiopurine-induced leukopenia. Nat Genet 2014;46:1017-20.

7. Kapoor G, Sinha R, Naithani R, Chandgothia M. Thiopurine Smethyltransferase gene polymorphism and 6-mercaptopurine dose intensity in Indian children with acute lymphoblastic leukaemia. Leuk Res 2010;34:1023-6.

8. Murugesan R, Vahab SA, Patra S, Rao R, Rao J, Rai P, et al. Thiopurine S-methyltransferase alleles, TPMT *2, *3B and *3C, and genotype frequencies in an Indian population. Exp Ther Med 2010;1:121-7.

9. Desire S, Balasubramanian P, Bajel A, George B, Viswabandya A, Mathews V, et al. Frequency of TPMT alleles in Indian patients with acute lymphatic leukaemia and effect on the dose of 6mercaptopurine. Med Oncol 2010;27:1046-9.

10. Umamaheswaran G, Krishnakumar D, Kayathiri D, Rajan S, Shewade DG, Dkhar SA, et al. Inter and intra-ethnic differences in the distribution of the molecular variants of TPMT, UGT1A1 and MDR1 genes in the South Indian population. Mol Biol Rep 2012;39:6343-51.

11. Dorababu P, Naushad SM, Linga VG, Gundeti S, Nagesh N, Kutala VK, et al. Genetic variants of thiopurine and folate metabolic pathways determine 6-MP mediated haematological toxicity in childhood ALL. Pharmacogenomics $2012 ; 13: 1001-8$.

12. Iyer SN, Tilak AV, Mukherjee MS, Singhal RS. Genotype frequencies of drug-metabolizing enzymes responsible for purine and pyrimidine antagonists in a healthy Asian-Indian population. Biochem Genet 2012;50:684-93.

13. Digumarti R, Gundeti S, Kalpathi KI, Linga VG, Patchva DB, Pillai A. Thiopurine methyltransferase polymorphisms in children with acute lymphoblastic leukemia. Indian J Med Paediatr Oncol 2014;35:276-80.

14. Davavala SK, Desai DC, Abraham P, Ashavaid T, Joshi A, Tarun Gupta, et al. Prevalence of TPMT polymorphism in Indian patients requiring immunomodulator therapy and its clinical significance. Indian J Gastroenterol 2014;33:41-5.

15. Anstey A, Lennard L, Mayou SC, Kirby JD. Pancytopenia related to azathioprine-an enzyme deficiency caused by a common genetic polymorphism: a review. J R Soc Med 1992;85:752-6.

16. Appell ML, Berg J, Duley J, Evans WE, Kennedy MA, Lennard L, et al. Nomenclature for alleles of the thiopurine methyltransferase gene. Pharmacogenet Genomics 2013;23: 242-8.

17. Collie-Duguid ES, Pritchard SC, Powrie RH, Sludden J, Collier $\mathrm{DA}, \mathrm{Li} \mathrm{T}$, et al. The frequency and distribution of thiopurine methyltransferase alleles in Caucasian and Asian populations. Pharmacogenetics 1999;9:37-42.

18. Derijks LJ, Wong DR. Pharmacogenetics of thiopurines in inflammatory bowel disease. Curr Pharm Des 2010;16:145-54. 
19. Gisbert JP, Gomollón F. Thiopurine-induced myelotoxicity in patients with inflammatory bowel disease: a review. Am J Gastroenterol 2008;103:1783-800.

20. Wiesner R, Rabkin J, Klintmalm G, McDiarmid S, Langnas A, Punch J, et al. A randomized double-blind comparative study of mycophenolate mofetil and azathioprine in combination with cyclosporine and corticosteroids in primary liver transplant recipients. Liver Transpl 2001;7:442-50.

21. Breen PD, Marinaky AM, Areenas M, Hayes PC. Pharmacogenetic association with adverse drug reactions to azathioprine immunosuppressive therapy following liver transplantation. Liver Transpl 2005;11:826-33.

22. Liu YP, Xu HQ, Li M, Yang X, Yu S, Fu WL, et al. Association between thiopurine S-methyltransferase polymorphisms and azathioprine-induced adverse drug reactions in patients with autoimmune diseases: a meta-analysis. PLoS One 2015;10:e0144234. Doi:10.1371/journal.pone.0144234

23. Stolk JN, Boerbooms AM, de Abreu RA, de Koning DG, van Beusekom HJ. Reduced thiopurine methyltransferase activity and development of side effects of azathioprine treatment in patients with rheumatoid arthritis. Arthritis Rheum 1998;41:1858-66.

24. Gazouli M, Pachoula L, Panayotou L, Chouliaras G, Anagnou NP, Chroussos G. Thiopurine methyltransferase genotype and thiopurine S-methyltransferase activity in Greek children with inflammatory bowel disease. Ann Gastroenterol 2012;25:249-53.

25. Lee YJ, Hwang EH, Park JH, Shin JH, Kang B, Kim SY. NUDT15 variant is the most common variant associated with thiopurine-induced early leukopenia and alopecia in Korean paediatric patients with Crohn's disease. Eur J Gastroenterol Hepatol 2016;28:475-8.

26. Liang DC, Yang CP, Liu HC, Jaing TH, Chen SH, Hung IJ, et al. NUDT15 gene polymorphism related to mercaptopurine intolerance in Taiwan Chinese children with acute lymphoblastic leukaemia. Pharmacogenomics J 2015;15:441-51.

27. Yang S, Hong M, Baek J, Choi H, Zhao W. A common missense variant in NUDT15 confers susceptibility to thiopurine-induced leukopenia. Nature Genetics 2014;46:1017-20.

28. Yang JJ, Landier W, Yang W, Liu C, Hageman L, Cheng C, et al. Inherited NUDT15 variant is a genetic determinant of mercaptopurine intolerance in children with acute lymphoblastic leukaemia. J Clin Oncol 2015;33:1235-42.

\section{How to cite this article}

- Sagi Sasidharan, Emmanuel James, Sudhindran S. PREscreening TPMT status of liver transplant patients for azathioprine therapy-A single centre experience from South India. Int J Pharm Pharm Sci 2017;9(2):84-88. 